\title{
MEASUREMENTS IN THE VT 400 AIR TURBINE
}

\author{
Marek Klimko*, Daniel OKresa \\ Department of Power System Engineering, Faculty of Mechanical Engineering, University of West Bohemia in \\ Pilsen, Univerzitni 22, 30614 Pilsen, Czech Republic \\ * corresponding author: klimko@kke.zcu.cz
}

\begin{abstract}
This paper presents a basic description of measurements on the experimental air turbine located in the laboratories of the Department of Power System Engineering (KKE). The research on this turbine focuses on the flow in a one-stage air turbine. It monitors the influence of the spatial formation of the blades on the efficiency of the stage. A new geometry with reaction blading is currently being tested. This work has been carried out in cooperation with an industrial partner, Doosan Skoda Power (DSPW).
\end{abstract}

KEYWORDS: air turbine, pressurized blading, pneumatic probe.

\section{INTRODUCTION}

Steam turbine constructers consider the methodology and the rules for calculating blading efficiency, when designing turbine stages, to be one of the most valuable and most confidential parts of their know-how. Guaranteed efficiency values are one of the key factors in the competition to retain and gain customers. Obtaining new data for specifying the so-called efficiency prediction, and also research focused on optimizing efficiency prediction, are important long-term development objectives for all steam turbine producers. Generally, blade spatial forming is one of the main instruments for increasing blading efficiency. It focuses particularly on reducing the influence of so-called secondary flow and related losses, but also deals with targeted redistribution of particular flow parameters, not only along the length of the blades, but also within the stage, or indeed within the whole flow section.

\section{CoOperation ON THE DEVELOPMENT OF BLADING}

Doosan Skoda Power (DSPW) has engaged in intense development of new types of blading in recent years, and cooperation with the Department of Power System Engineering (KKE) has been an integral aspect of this development work.

Between 2000 and 2005, the development work aimed at forming stationary blades. Variants with both lean and compound lean peripheral inclination, and also a controlled flow blade, were investigated (see Figure 1). These types of blading were tested on a SKODA 1MW trial steam turbine, and simultaneous tests were carried out on the KKE air turbine at the University of West Bohemia in Pilsen.

The studies concentrated on forming stator blades, while preserving the original prismatic moving blades. One of the outcomes of the research, which was carried out within the framework of several grant-funded projects (FD-K/011 ${ }^{1}$ GA101/01/1448 $q^{2}$, was the design by DSPW of the so-called banana blade. Some results of the cooperation between DSPW and KKE have been presented, e.g. in [1-4].

In the following period, DSPW, a traditional producer of action conception turbines, began to develop 3D blading with so-called slightly increased hub reaction. This blading included the formation of both stationary blades and moving blades.

Compound lean blading, combined with controlled flow access of stationary blades, supplemented by an appropriately formed (twisted) moving blade, was designed and tested within the framework of grantfunded projects (e.g. FT-TA/085 $5^{3}$ FT-TA2/037 7 FTTA5/067 and ongoing cooperation. Experimental testing of these "Full3D" stages was one of the principal topics of the cooperation between KKE, a university department, and DSPW, an industrial company, between 2008 and 2012. Three variants with different compactness of the blades were tested stepwise (Figure 2). The results were published for example in $[5] 9]$. This development raised the efficiency by approx. $2 \%$ in the HP component and by $1.5 \%$ in the MP component, in comparison with classic prismatic or warped blading. In many cases, improved design principles have been transferred into practical applications.

Stages with an increased hub reaction basically represent a developmental transition between action and reaction stage conceptions. Current developments in 3D blading have been leading DSPW logically to-

\footnotetext{
${ }^{1}$ Project FD-K/011 - Development of high efficiency steam turbines 150-500 MW. (2001-2003, MPO/FD)

${ }^{2}$ Project GA101/01/1448 - Development of a new generation of steam turbine high-pressure blades with low losses (2001-2003, GA0/GA)

${ }^{3}$ Project FT-TA/085 - Steam turbine of high efficiency (20042006, MPO/FT)

${ }^{4}$ Project FT-TA2/037 - Steam turbine for power units with high steam parameters. (2005-2007, MPO/FT)

${ }^{5}$ Project FT-TA5/067 - Research of non-stationaryflow in an axial-flow turbine stage(2008-2010, MPO/FT)
} 


\begin{tabular}{l|cccc}
\hline Blading type & Prismatic & Lean & $\begin{array}{c}\text { Compound } \\
\text { Lean }\end{array}$ & $\begin{array}{c}\text { Compound } \\
\text { Twist }\end{array}$ \\
\hline Blade shape & & & & \\
\hline
\end{tabular}

Figure 1. Formation of stator blades.

\begin{tabular}{llll}
\hline $\begin{array}{l}\text { Stationary blade } \\
\text { variant } 1(2010)\end{array}$ & $\begin{array}{l}\text { Stationary blade } \\
\text { variant 2 }(2011)\end{array}$ & $\begin{array}{l}\text { Stationary blade } \\
\text { variant } 3(2012)\end{array}$ & Moving blade \\
\hline &
\end{tabular}

Figure 2. Forms of blades tested in the "Full3D" stage.

wards reaction blading. A vast internal developmental project has been proceeding since 2011, when the first stage of the development focused on blading for the HP component of turbines with an approximate efficiency of $300 \mathrm{MW}$. The goal was to increase the efficiency of the HP component of a steam turbine by up to $1.6 \%$ in comparison with the efficiency of commonly designed HP components with blading with a slightly increased hub reaction. The development of new profiles and subsequent experimental verification of the new conception formed a part of project FRTI3/432 6 which was solved in cooperation with the Aerospace Research and Test Establishment in Prague. Complex verification on a Skoda $10 \mathrm{MW}$ trial steam turbine forms a significant part of the development of reaction blading. KKE is also involved in followup research work, and collaborates in experimental testing of reaction blading on air turbines.

However, the development trends and objectives of individual competing companies have not been focused and profiled only on action blading or reaction blading. Much work is also being done on so-called variable reaction stages, i.e. the optimized use of blades with a different reaction, with regard to the design requirements and attempts to achieve higher efficiency. This is a present-day developmental direction at DSPW, and it foms the topic of a follow-up internal project, where the application of reaction blades to high efficiency turbines is also being investigated.

\footnotetext{
${ }^{6}$ FR-TI3/432 - Complex development of a turbine reaction stage with high efficiency (2011-2013, MPO/FR)
}

\section{EXPERIMENTAL AIR TURBINE AT KKE}

The experimental air turbine at KKE is a single-stage air turbine located in the compressor suction. The turbine is a model of a high-pressure steam turbine component stage on a scale of 1:2. In addition to almost constant air input parameters, this layout also provides easy access to the turbine and to the measuring points.

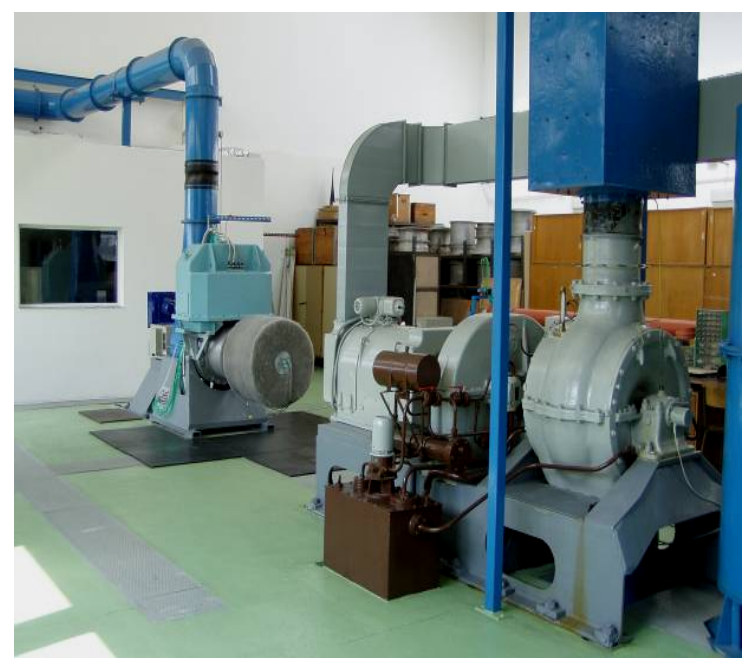

FiguRE 3. View into the laboratory.

A part of the machine is the direct dynamometer, which determines the speed and the resulting moment. Air, the volume of which is measured by a nozzle, 


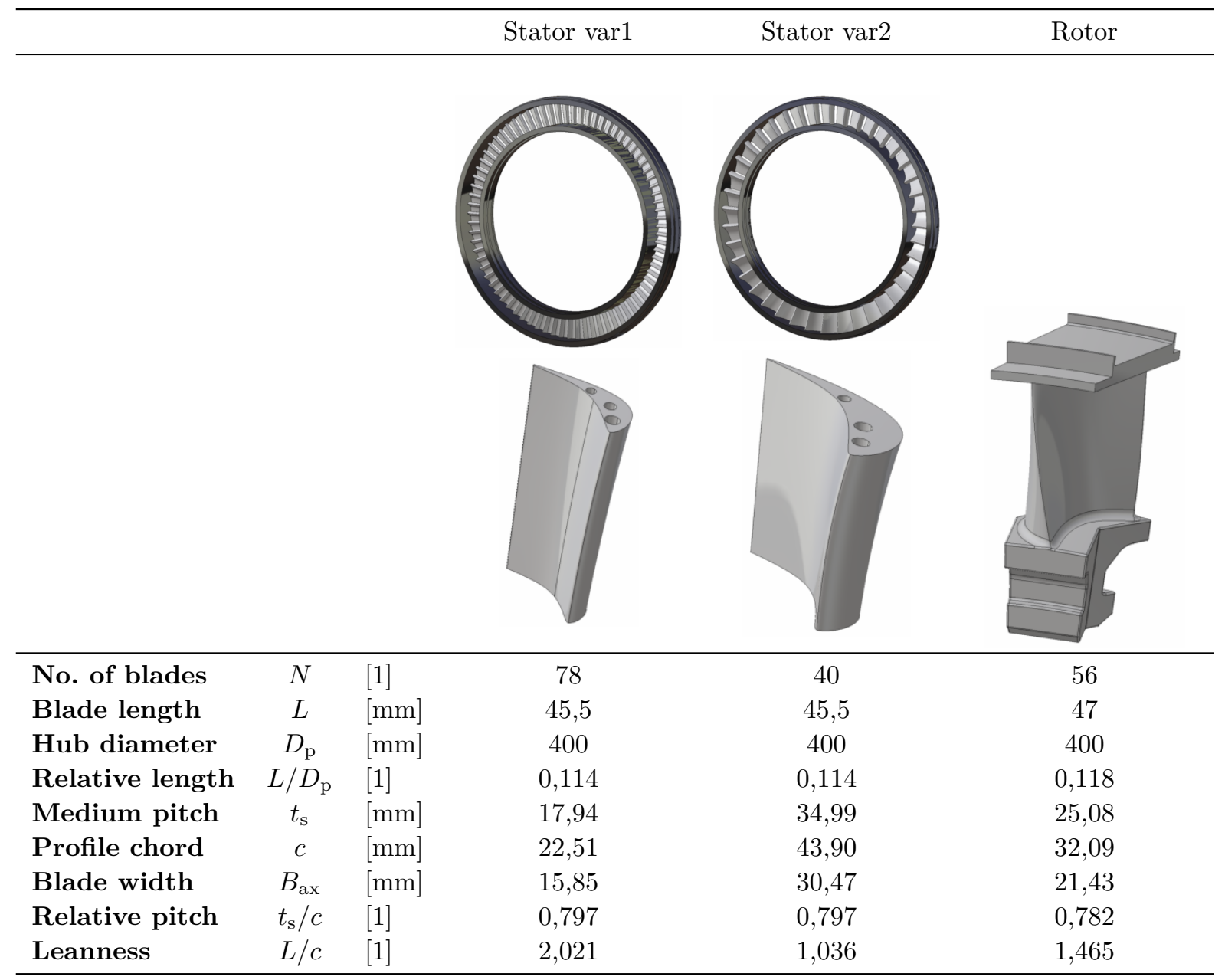

FiguRE 4. Basic geometric characteristics.

leaves the compressor pressure discharge and goes out of the laboratory. The turbine is equipped with a traverse device. The traverser enables the probe to move radially (under the blade hub section and above the blade tip), and peripherally (across two stationary blade pitches). It also allows the probe to turn automatically in the flow direction. This enables thorough measurements of the flow field behind stationary and moving blades. There are several static pressure extractors on the turbine - in front of the stage, inside it, and behind it - always on the hub section and tip diameter. There are holes at the input, for inserting e.g. a Prandtl probe, and for measuring the input flow. All pressures are scanned by a fast, 16-channel pressure transducer. Temperatures are scanned by a resistance thermometer in front of and behind the stage. The probe measurement and motion are automatic; the utility program is created in LabView 7.

\section{NEW BLADING FOR THE EXPERIMENT}

In 2013, DSPW proposed two variants of a stage designed for testing on the air turbine of the University of West Bohemia, in accordance with newly prepared methodologies, and using new profiles for reaction

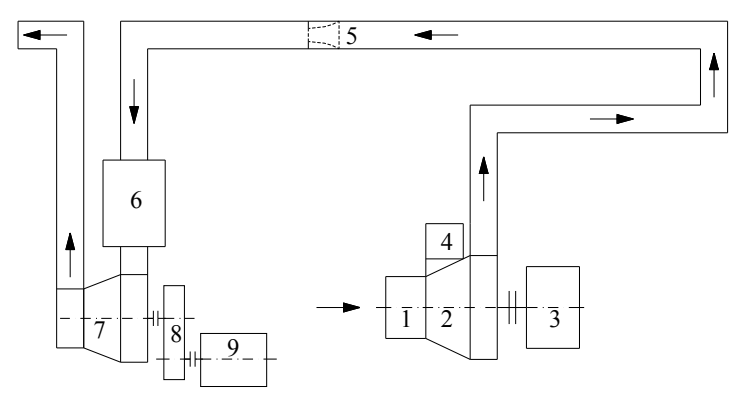

Figure 5. Scheme of the device: 1 - Filter, $2-$ Turbine, 3 - Dynamometer, 4 - Traverser, 5 - Nozzle, 6 - Silencer, 7 - Compressor, 8 - Gearbox, 9 - Electric motor.

blading. The aim was to verify the design data concerning aerodynamics, and to obtain data for the specifications of a loss model of the reaction stages. The variants differ in the leanness of the stationary blade, the main parameter influencing the creation of secondary losses. The basic geometric data are summarized in Figure 4. The figure has been produced, and the first tests the first tests were performed early in 2015. All the experiments were completed by the middle of 2015 . 


\section{Evaluation process}

Measurements behind the stator and rotor blades were made with the use of a 5-hole pneumatic probe which allows movement around its own axis and also in the radial and circumferential directions.

Calculating the air flow rate. The air flow rate is calculated using the ASME standard bases

$$
\dot{m}_{\mathrm{V}}=f\left(p_{\mathrm{c}}, \Delta p_{\mathrm{c}}, T_{\text {out }}\right)
$$

Calculating the isentropic gradient of the stage. The isentropic gradient of the stage is considered to lie between static pressures

$$
\begin{gathered}
T_{02 \mathrm{iz}}^{\mathrm{INT}}=T_{0 \mathrm{~s}}^{\mathrm{INT}}\left(\frac{p_{2 \mathrm{~s}}^{\mathrm{INT}}}{p_{0 \mathrm{~s}}^{\mathrm{INT}}}\right)^{\frac{\kappa-1}{\kappa}}, \\
H_{\mathrm{iz}}^{\mathrm{ST}}=c_{p}\left(T_{0 \mathrm{~s}}^{\mathrm{INT}}-T_{02 \mathrm{iz}}^{\mathrm{INT}}\right) \Rightarrow c_{02 \mathrm{iz}}=\sqrt{2 H_{\mathrm{iz}}^{\mathrm{ST}}} .
\end{gathered}
$$

Calculating the input and output velocity. The input and output velocities are axial velocities

$$
\begin{array}{ll}
c_{0 a}=c_{0}=\frac{\dot{m}_{\mathrm{V}}}{s_{0} \rho_{0 \mathrm{~s}}}, & \rho_{0 \mathrm{~s}}=\frac{p_{0 \mathrm{~s}}^{\mathrm{INT}}}{R_{\mathrm{V}} T_{0 \mathrm{~s}}^{\mathrm{INT}}}, \\
c_{2 a} \approx c_{2}=\frac{\dot{m}_{\mathrm{V}}}{S_{2} \rho_{2 \mathrm{~s}}}, & \rho_{2 \mathrm{~s}} \approx \rho_{02 \mathrm{iz}}=\frac{p_{2 \mathrm{~s}}^{\mathrm{INT}}}{R_{\mathrm{V}} T_{02 \mathrm{iz}}^{\mathrm{INT}}} .
\end{array}
$$

Calculating the total output state.

$$
T_{0 \mathrm{c}}^{\mathrm{INT}}=T_{0 \mathrm{~s}}^{\mathrm{INT}}+\frac{c_{0}^{2}}{2 c_{p}}
$$

Calculating the performance and effective pressure drop.

$$
\begin{gathered}
P=M_{k} \omega=M_{k} \frac{2 \pi n}{60}=P_{\mathrm{obv}}-P_{f}, \\
H^{\mathrm{ST}}=\frac{P_{\mathrm{obv}}}{\dot{m}_{\mathrm{V}}}=\frac{P+P_{f}}{\dot{m}_{\mathrm{V}}}=c_{p}\left(T_{0 \mathrm{c}}^{\mathrm{INT}}-T_{2 \mathrm{c}}^{\mathrm{INT}}\right) .
\end{gathered}
$$

Calculating the efficiency and the moment of torsion.

$$
\begin{gathered}
\eta_{\mathrm{ts}}^{\mathrm{ST}}=\frac{H^{\mathrm{ST}}}{H_{\mathrm{iz}}^{\mathrm{ST}}+\frac{c_{0}^{2}}{2}}=\frac{H^{\mathrm{ST}}}{c_{p}\left(T_{0 \mathrm{~s}}^{\mathrm{INT}}-T_{02 \mathrm{iz}}^{\mathrm{INT}}\right)+\frac{c_{0}^{2}}{2}}, \\
\eta_{\mathrm{tt}}^{\mathrm{ST}}=\frac{H^{\mathrm{ST}}}{H_{\mathrm{iz}}^{\mathrm{ST}}+\frac{c_{0}^{2}}{2}+\frac{c_{2}^{2}}{2}} .
\end{gathered}
$$

Traversing behind stationary blades. To evaluate the traversing data, we need to know the integral values and we need data from the 5 -hole pneumatic probe, after re-calculation according to the calibration $\left(p_{1 \mathrm{c}}, p_{1 \mathrm{~s}}, \phi, \theta\right)$.

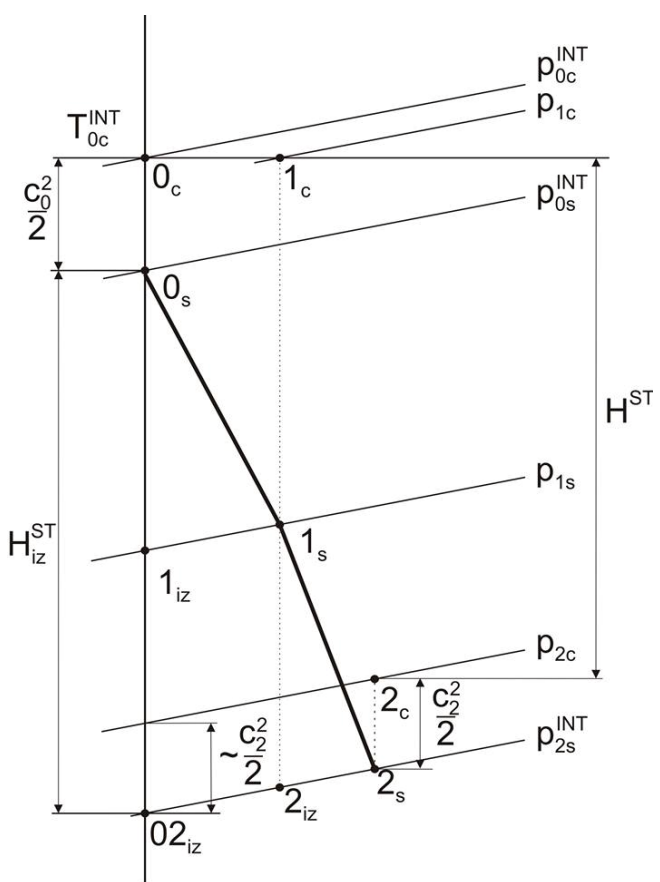

Figure 6. $T-s$ expansion diagram.

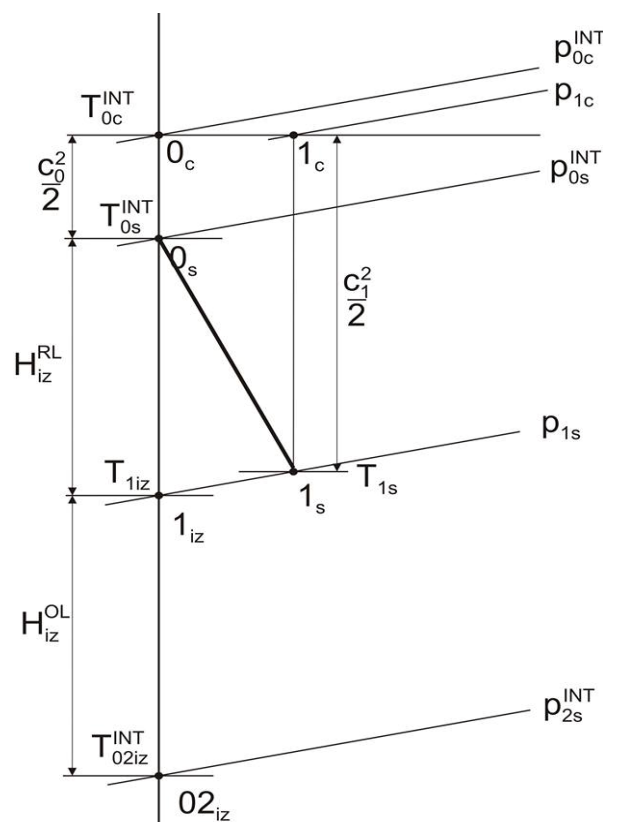

FiguRE 7. $T-s$ expansion diagram.

Calculating the gradient and the reaction of stationary blades.

$$
\begin{gathered}
T_{1 \mathrm{iz}}=T_{0 \mathrm{~s}}^{\mathrm{INT}}\left(\frac{p_{1 \mathrm{~s}}}{p_{0 \mathrm{~s}}^{\mathrm{INT}}}\right)^{\frac{\kappa-1}{\kappa}}, \\
H_{\mathrm{iz}}^{\mathrm{RL}}=c_{p}\left(T_{0 \mathrm{~s}}^{\mathrm{INT}}-T_{1 \mathrm{iz}}\right), \\
H_{\mathrm{iz}}^{\mathrm{OL}}=c_{p}\left(T_{1 \mathrm{iz}}-T_{02 \mathrm{iz}}^{\mathrm{INT}}\right)=H_{\mathrm{iz}}^{\mathrm{ST}}-H_{\mathrm{iz}}^{\mathrm{RL}} .
\end{gathered}
$$

Velocity triangles.

$$
T_{1 \mathrm{~s}}=T_{0 \mathrm{c}}^{\mathrm{INT}}\left(\frac{p_{1 \mathrm{~s}}}{p_{1 \mathrm{c}}}\right)^{\frac{\kappa-1}{\kappa}},
$$




$$
\begin{gathered}
c_{1}=\sqrt{2 c_{p}\left(T_{0 \mathrm{c}}^{\mathrm{INT}}-T_{1 \mathrm{~s}}\right)}, \\
c_{1 a}=c_{1} \cos \theta \cos (90-\varphi), \\
c_{1 u}=c_{1} \cos \theta \sin (90-\varphi), \\
c_{1 r}=c_{1} \sin \theta \\
w_{1 u}=c_{1 u}-u_{1}, \\
w_{1}=\sqrt{c_{1 a}^{2}+c_{1 u}^{2}}, \\
\beta_{1 t}=\operatorname{acos} \frac{w_{1 u}}{w_{1}} .
\end{gathered}
$$

Calculating the efficiency of stationary blades.

$$
\eta^{\mathrm{RL}}=\frac{T_{0 \mathrm{c}}^{\mathrm{INT}}-T_{1 \mathrm{~s}}}{T_{0 \mathrm{c}}^{\mathrm{INT}}-T_{1 \mathrm{iz}}}=\frac{\frac{c_{1}^{2}}{2}}{H_{\mathrm{iz}}^{\mathrm{RL}}+\frac{c_{0}^{2}}{2}} .
$$

Traversing behind moving blades. To evaluate the traversing data, we need to know the integral values, and we need data from the 5 -hole pneumatic probe, after re-calculation according to the calibration $\left(p_{2 \mathrm{c}}, p_{1 \mathrm{~s}}, \varphi, \theta\right)$.

The state in front of moving blades.

$$
\begin{gathered}
\rho^{\mathrm{SS}}, \frac{c_{1}}{c_{02 \mathrm{iz}}}, \frac{w_{1}}{c_{02 \mathrm{iz}}}, \\
H_{\mathrm{iz}}^{\mathrm{RL}}=\left(1-\rho^{\mathrm{SS}}\right) H_{\mathrm{iz}}^{\mathrm{ST}}, \\
p_{1 s}=p_{0 \mathrm{~s}}^{\mathrm{INT}}\left(\frac{T_{1 \mathrm{iz}}}{T_{0 \mathrm{~s}}^{\mathrm{INT}}}\right)^{\frac{\kappa}{\kappa-1}}, \\
c_{1}=\left(\frac{c_{1}}{c_{02 \mathrm{iz}}}\right) c_{02 \mathrm{iz}}, \\
w_{1}=\left(\frac{w_{1}}{c_{02 \mathrm{iz}}}\right) c_{02 \mathrm{iz}}, \\
T_{1 \mathrm{~s}}=T_{0 \mathrm{c}}^{\mathrm{INT}}-\frac{c_{1}^{2}}{2 c_{p}} .
\end{gathered}
$$

Calculating the expansion of moving blades.

$$
\begin{gathered}
T_{1 w}=T_{1 \mathrm{~s}}+\frac{w_{1}^{2}}{2 c_{p}}, \\
T_{2 \mathrm{iz}}=T_{1 \mathrm{~s}}\left(\frac{p_{2 \mathrm{~s}}}{p_{1 \mathrm{~s}}}\right)^{\frac{\kappa-1}{\kappa}} .
\end{gathered}
$$

Estimating the velocity $c_{2}$.

$$
\begin{gathered}
T_{2 \mathrm{ciz}}=T_{1 \mathrm{~s}}\left(\frac{p_{2 \mathrm{c}}}{p_{1 \mathrm{~s}}}\right)^{\frac{\kappa-1}{\kappa}}, \\
\tilde{c}_{2}=\sqrt{2 c_{p}\left(T_{2 \mathrm{ciz}}-T_{2 \mathrm{iz}}\right),} \\
\tilde{c}_{2 a}=\tilde{c}_{2} \cos \theta \cos (90-\varphi), \\
\tilde{c}_{2 u}=\tilde{c}_{2} \cos \theta \sin (90-\varphi), \\
\tilde{w}_{2 u}=\tilde{c}_{2 u}-u_{2}, \\
\tilde{w}_{2}=\sqrt{\tilde{c}_{2 a}^{2}+\tilde{w}_{2 u}^{2} .}
\end{gathered}
$$

\section{Recalculating the expansion.}

$$
\begin{gathered}
T_{2 \mathrm{~s}}=T_{1 w}-\frac{\tilde{w}_{2}^{2}}{2 c_{p}}, \\
T_{2 \mathrm{c}}=T_{2 \mathrm{~s}}\left(\frac{p_{2 \mathrm{c}}}{p_{2 \mathrm{~s}}}\right)^{\frac{\kappa-1}{\kappa}}, \\
c_{2}=\sqrt{2 c_{p}\left(T_{2 \mathrm{c}}-T_{2 s}\right)}, \\
c_{2 a}=c_{2} \cos \theta \cos (90-\varphi), \\
c_{2 u}=c_{2} \cos \theta \sin (90-\varphi), \\
c_{2 r}=c_{2} \sin \theta \\
w_{2 u}=c_{2 u}-u_{2}, \\
w_{2}=\sqrt{c_{2 a}^{2}+w_{2 u}^{2}}, \\
\beta_{2 f}=\operatorname{acos} \frac{w_{2 u}}{w_{2}} .
\end{gathered}
$$

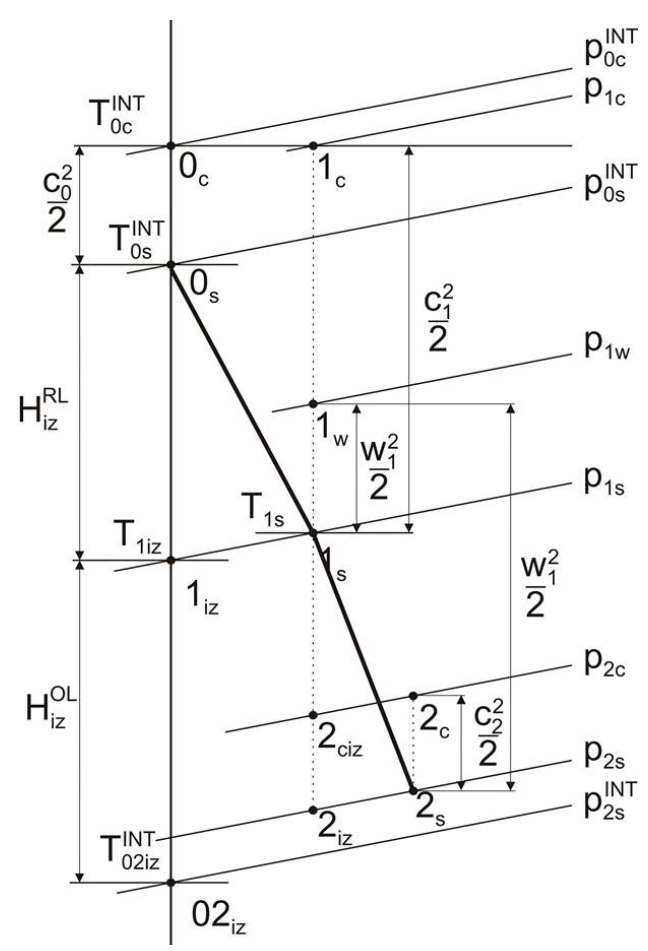

FiguRE 8. $T-s$ expansion diagram.

Efficiency of moving blades.

$$
\eta^{\mathrm{OL}}=\frac{T_{1 w}-T_{2 \mathrm{~s}}}{T_{1 w}-T_{2 \mathrm{iz}}} .
$$

\section{Results of EXPERIMENTS}

The variant of the stage with no leanstationary blade was chosen for the initial experiments. All experiments proceeded according to the established methodology. First, integral characteristics depending on the velocity ratio $u / c$ were identified. Individual measurements were executed at a constant speed; and changes in the 


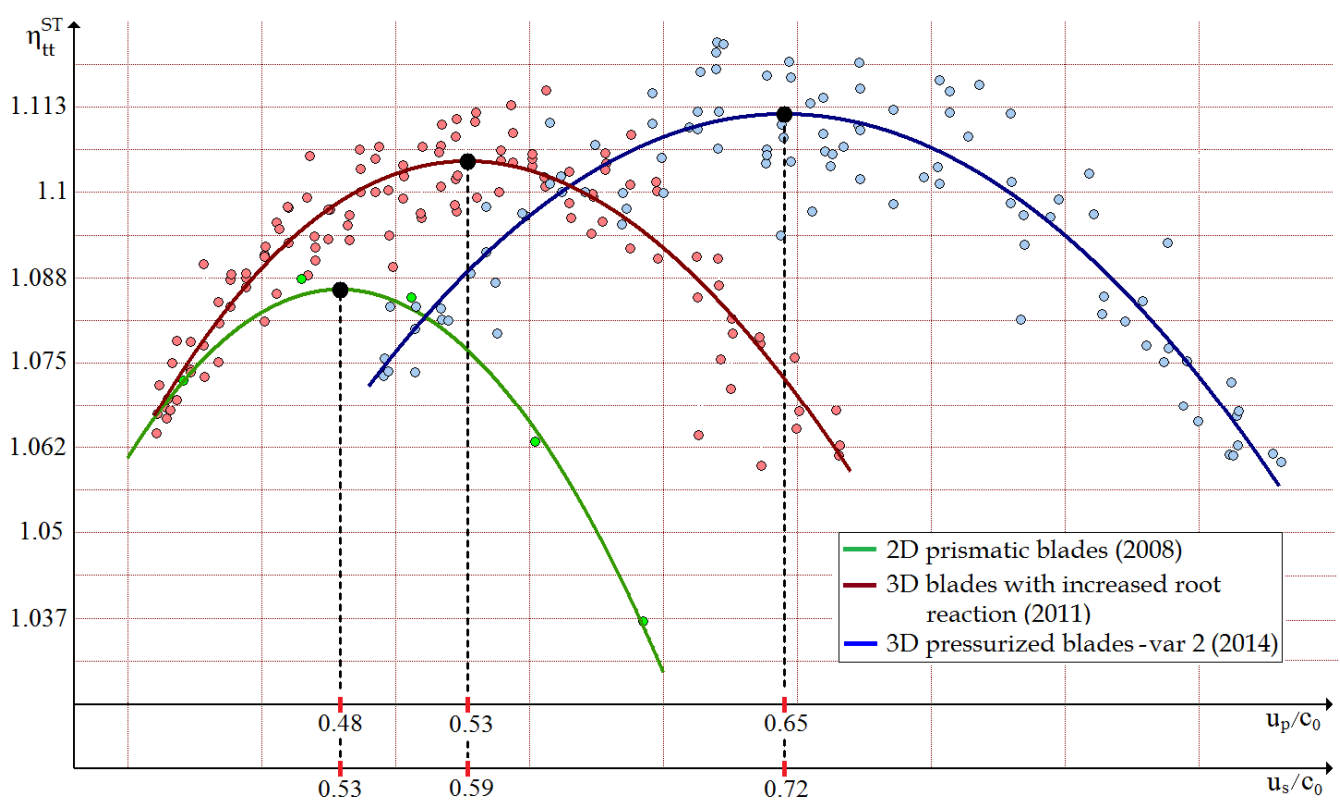

Figure 9. A comparison of the results for different blading variants.

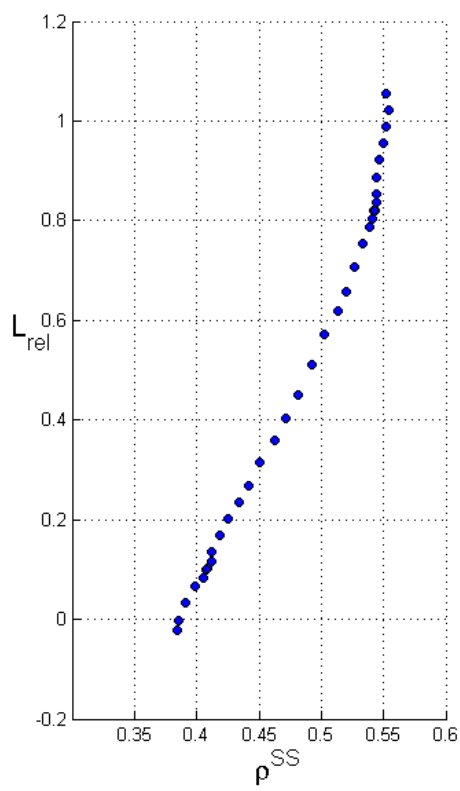

FiguRE 10. The course of the reaction along the relative length of the blade.

values of the velocity ratio $u / c$ occurred due to the change in the pressure drop in the turbine.

The measurements were made at several levels of speed (within the range of approx. 2000-3000 revolutions per minute), which led to changes in the pressure drop, the Mach number and partly also the Reynolds number. These measurements were used to set the optimal operating state in which further experiments can proceed, particularly measurements by a 5 -hole pneumatic probe of the flow fields behind stationary

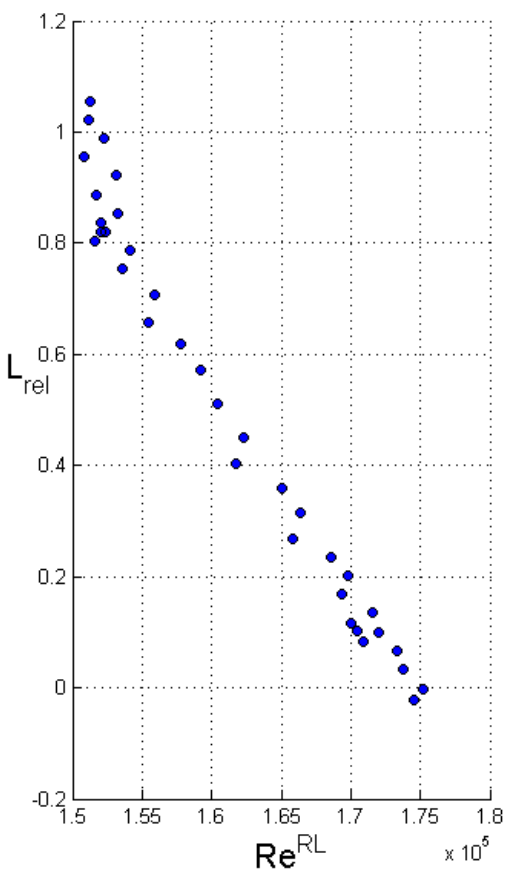

Figure 11. The course of the Reynolds number along the blade.

and moving blades.

One of the basic properties of a turbine stage is the dependence of the peripheral efficiency on the velocity ratio $u / c$. These dependences provide an idea about the optimal operating regime for the stage in order to achieve maximum efficiency. The optimum operating state differs according to the type of blading. The results of the initial experiments are presented in a 


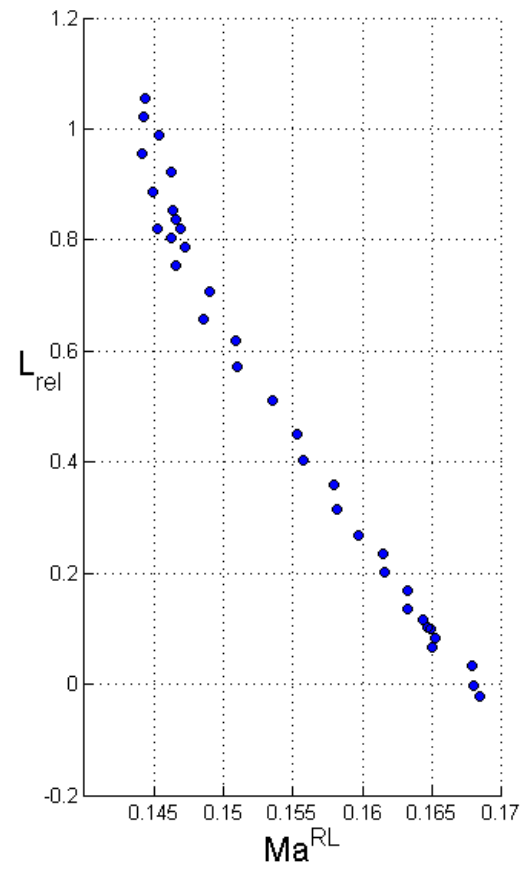

Figure 12. The course of the Mach number along the blade.

graph (Figure 9), in comparison with the results of previous experiments.

This comparison shows a sequential contribution to relative peripheral stage efficiencies. Existing test results show a progressive trend toward increasing efficiency, and originally confirm that the newly designed reaction blading is a well-selected development direction. By determining an optimal operating regime, we have moved towards another phase, in which the flow fields behind both stationary blades and moving blades will be measured.

The efficiency results are presented as relative values. The data from the measurements are the property of DSPW. It is apparent from the reaction dependence along the length of the blade that a reaction value around 0.5 is reached in the middle of the blade, which corresponds to our expectations.

The average Mach number value in the middle of the blade is 0.15 , which means that it is a deeply subsonic flow. The Reynolds number oscillates around 160000 .

\section{Conclusion}

Experimental verification of new reaction blading on air turbines is still in its initial phase. However, the preliminary results already show further substantial improvement of the stage efficiency (by $0.7 \%$ (estimated) in comparison with the Full3D variant, and by up to approximately $2 \%$ in comparison with prismatic blades). A further slight increase in peripheral efficiency is expected for the second tested variant with lean stationary blades. For the future, the flow fields behind stationary blades and, subsequently, behind moving blades, will be measured using a 5-hole pneumatic probe. The measurements will be carried out in cooperation with DSPW. The output of the measurements will be the distribution of losses and angles, or the reaction along the length of the blade.

\section{LIST OF SYMBOLS}

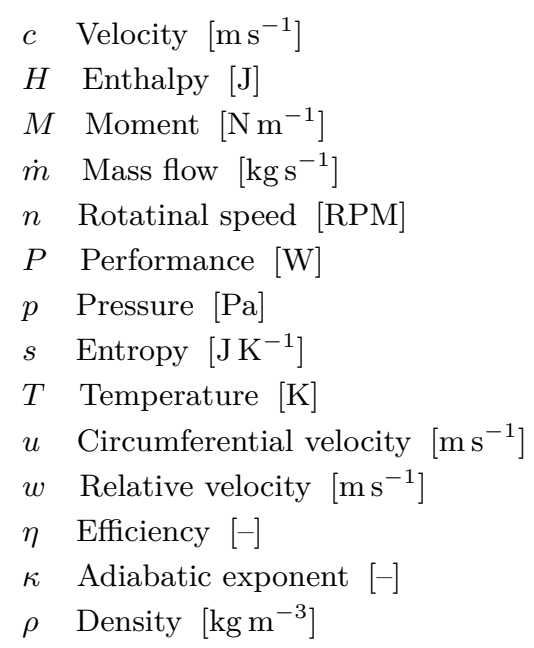

SUPERSCRIPTS

INT Integral characteristics

OL Bucket

RL Nozzle

ST Stage

SuBSCRIPTS

c absolute

iz isentropic

s static

ts total to static

tt total to total

\section{ACKNOWLEDGEMENTS}

This study originated within the student project SGS2014-070 (Increase of efficiency, reliability and lifespan of power system machines and equipment 3 ), and the project CZ.1.05/2.1.00/03.0108SUSEN (Sustainable energetics).

\section{REFERENCES}

[1] J. Vomlela. Experimental and numerical development of turbine blades of high efficiency. In 5th European conference on turbomachinery, pp. 699-708. Praha: A.S.I., 2003.

[2] J. Vomlela, P. Milčák. The development of high-efficiency turbine blades. In Cieplne maszyny przeplywowe. Turbomachinery., pp. 557-564. Technical University of Łódź, 2005.

[3] B. Haller. Full 3d turbine blade design. In Lecture series "Secondary and Tip Clearance Flows in Axial Turbines". von Karman Institute for Fluid Dynamics, 1997.

[4] C. Sieverding. Recent progress in the understanding of basic aspects of secondary flows in turbine blade passages. Journal of Engineering for Gas Turbines and Power 107:248-257, 1985. 
[5] P. Milčák, K. Sobczak. Experimental and numerical investigations of a flow in the stage with compound lean and compound twist stator blades. In Power System Engineering, Thermodynamics \& Fluid Flow ES 2007, pp. 153-160. Západočeská univerzita v Plzni, 2007.

[6] S. Harrison. The influence of blade lean on turbine losses. J Turbomach 114(1):184-190, 2016. DOI:10.1115/1.2927982

[7] P. Milčák, M. Hoznedl. Measurement of flow fields on a turbine stage with 3D blades. In Experimental Fluid Mechanics, pp. 417-422. Technical University of Liberec, 2010 .
[8] P. Milčák, M. Hoznedl, P. Žitek. Measurement on stages with 3D bladings and different relative width of stator blades. In EFM11 - Experimental Fluid Mechanics 2011, vol. 25 of EPJ Web of Conferences. 2012. DOI:10.1051/epjconf/20122501054.

[9] P. Milčák, P. Žitek, M. Hoznedl. Comparison of results from experimental testing of three variants of turbine stage with modern 3D blades. In EFM12 Experimental Fluid Mechanics 2012, vol. 45 of EPJ Web of Conferences. 2013. DOI:10.1051/epjconf/20134501063 